Asian Journal of Economic Modelling

$\operatorname{ISSN}(e): \quad 2312-3656$

$\operatorname{ISSN}(p): \quad 2313-2884$

DOI: $10.18488 /$ journal.8.2018.64.419.427

Vol. 6, No. 4, 419-427

(C) 2018 AESS Publications. All Rights Reserved.

URL: wwrwaessweb.com

check for
updates

\title{
IMPACT OF HEALTH EXPENDITURES ON LABOR FORCE PARTICIPATION: EVIDENCE FROM PAKISTAN
}

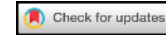

\author{
Abdur Rauf ${ }^{1+}$ \\ Maryyum Bashir ${ }^{2}$ \\ Kiran Asif ${ }^{3}$ \\ Sardar Fawad Saleem ${ }^{4}$ \\ 'Assistant Professor, Department of Economics, Abbottabad University of \\ Science and Technology, Havellian, Abbottabad, Pakistan \\ Email:ab.ranf.khattak@gmail.com \\ ${ }^{\circ}$ Lecturer, Kashmir Institute of Economics, University of Azad Jammu and \\ Kashmir, Muzafarabad, Pakistan \\ ${ }^{3}$ M.Sc student, Kashmir Institute of Economics, University of Azad Jammu \\ and Kashmir, Muzaffarabad, Pakistan

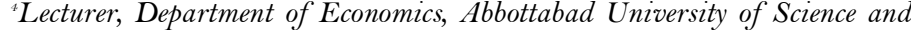 \\ Technology, Havellian, Abbottabad, Pakistan
}

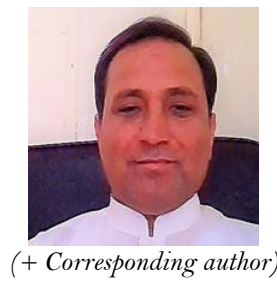

ABSTRACT

\author{
Article History \\ Received: 8 June 2018 \\ Revised: 13 August 2018 \\ Accepted: 4. September 2018 \\ Published: 28 September 2018

\section{Keywords} \\ Health \\ Labor force participation \\ Secondary school enrollment \\ Life Expectancy \\ Trade Openness \\ Investment
}

\begin{abstract}
The current study focused on health expenditures and labor force participation linkages taking Pakistan as a sample case. Data sample cover the period from 1972 to 2013. Economic survey of Pakistan and WDI were consulted for data collection and the estimated results were extracted by using Autoregressive Distributive Lag Model which revealed that there is positive association between health and labor force participation rate in Pakistan. Amongst the other variables, secondary school enrolment and Investment also has positive impacts on labor force participation in both long and short span of time. Life expectancy has adverse effects and trade openness is insignificant in a model. It is suggested that to encourage higher labor force participation government may increase its expenditures on basic health issues along with investment friendly policies. Furthermore it is also suggested that education may also be encouraged for productive labor in a country.
\end{abstract}

Contribution/ Originality: This study contributes to the existing literature by (i) employing an estimation method that recognizes uncertainty regarding the stationarity status of some variables, (ii) distinguishing short-run and long-run effects and (iii) one of the few studies that provides country specific evidence.

\section{INTRODUCTION}

Health, which valued as a part of human capital (Becker, 1964; Grossman, 1972) is a state of complete physical, mental and social well-being that helps in developing skills, knowledge and capabilities which are not only related to the productivity of individual but also for the demand of his labor. Healthy workers are tends to be more productive as good health will helps in education and thus skills which increase the productivity of individual. Poor health is likely to have an adverse effect on the performance of worker and leads to lower productivity which decrease the earning potential of individuals (Holt, 2010). Therefore a positive correlation exist between good health and high labor productivity.

Health and labour may not be linked only by productivity. The relative utility of the individual derived from income and time out of the labour market may be changed by the outset of some health problems, even if the productivity of individual is not affected by these problems. For instance, an individual with poor health may value 
leisure over work, because with ill health the time needed to care for one's health increases the burden of the work. Similarly, early withdrawals from the labour market become more attractive as a result of effect of poor health on life expectancy (Chirikos, 1993). These arguments also predict that poor health leads to decrease in labour supply and lower probability of labour force participation. As a result, the effect of health on labour supply can be estimated through influencing the capacity or ability to perform the requirements of the job or through influencing the preferences of the individuals. These two effects have not been differentiated in the literature (Chirikos, 1993).

In the light of above arguments it is clear that the probability of labour force participation decreases with poor health. However, it could also be argued that low earnings associated with poor health may have an income effect that could lead to increase in labour supply. The individuals with poor health need more health services and need to work more in order to meet the increased demand for health services.

Since the very beginning Pakistan has a high population growth. By population size it is the sixth largest country of the world. In 1950, with a current population growth, it will become the fifth largest populous country of the world. This increase in population put pressure on economy for food, infrastructure, employment and other basic services provision. In Pakistan, many efforts have been made to improve the health system but still it is not encouraging. Health delivery system is run by both state and non-state authorities. The distribution of health care facilities is unfair where the people living in urban areas have an easy access and for rural inhabitants the accessibility to basic health facilities are difficult. From the last 10 years the overall expenditure as a percentage of GDP is very less $(.5 \%-.8 \%)$ while the bench mark set by WHO is at least $6 \%$ of GDP. The per capita health spending is $\$ 36.2$ which is below the WHO'S low income countries benchmark of $\$ 86$.

Previous empirical studies find positive relation between health and labor supply but the exact direction of this association is not clear (Dwyer and Mitchell, 1999). This study is designed to finding the long and short run relationship between health indicators and labor force participation. This will helps in estimating the cost of health limitations to the economy. Very limited work has been done so far in this area in a context of Pakistan and the available literature focused on female labor participation and health relationship. The present study focuses on impact of health on overall labor force participation rate including both males and females in context of Pakistan.

Rest of the paper is organized as following. After introduction next chapter discuss the previous relevant studies on this topic, Data and methodology are discussed in section 3. Section 4 presents empirical analysis while conclusions and policy recommendations are discussed in last section of this study.

\section{LITERATURE REVIEW}

The previous literature discuss the health and labor force participation in three different ways, i.e. productivity, life expectancy and income effect. Majority of the literature explore the relation between productivity and health are primarily based on Becker (1964) human capital theory which suggest positive correlation between human health and its effects on their productivity. Life expectancy approach, argue that beside productivity there are some other aspects as well which also determine this relationship. As per this approach it is the health which influence the preferences between leisure and work, those of poor health will prefer leisure over work so that they can take care of their ill health. This decision will force them to leave labor market which shake their life expectancy (Chirikos, 1993). Income effect suggest positive correlation between the two. Ill health people need medical care and for medical care an individual needs to earn medical expenses (Dwyer and Mitchell, 1999; Cai and Kalb, 2006).

\subsection{General Empirical Studies}

Leung and Wong (2002) analyzed the interrelationship between health status and labour supply. For cross sectional data analysis were made by constructing three different simultaneous equations models. Findings of this study suggest strong evidence for health and labor supply while the individual estimation of the two equations were misleading. 
Cai and Kalb (2004) analyzed the effect of health on labour force participation in Australia. To control the endogeneity, this study used simultaneous equations approach. The potential endogeneity of the health variables, especially self-assessed health, in the labour force participation equation was observed by estimating the health equation and the labour force participation equation simultaneously. Different age groups were studied and it was found that good health increases the labor force participation in all groups.

Cai and Kalb (2006) also studied Australian society to investigate the health effects on labour force status of older-working age. The study used a random-effect approach that exploits the panel data nature of the HILDA survey and to control unobserved heterogeneity. The endogeneity of the health variable resulting from unobserved heterogeneity was accounted by introducing a health equation and allowing the error terms in the health equation and the labour force status equation to correlate. The model estimated in the study found that health has a significant effect on labour supply.

Pandey (2009) analyzed the hypothesis for Indian society. The study was based on 60 round data which was collected by National Sample Survey Organization (NSSO) in the period between January-June 2004 and estimated two equations simultaneously; for health and other for labour force participation. Full Information Maximum Likelihhood (to address endogeneity) and two-stage approach (for estimation) were used for the analysis. The estimated results found a significant and strong positive effect of health status on labour force participation in Indian society.

Cai (2010) employed a panel data simultaneous equation model to explore the relationship between health and labour force status. To obtain more efficient estimation results the study used panel data for controlling unobserved heterogeneity than using cross-sectional data. By using Household, Income and Labour Dynamics in Australia (HILDA) survey, the study found that health has positive and significant effect on labour force participation for both males and females. As for the reverse effect, it was found that labour force participation has a negative effect on male health but a positive effect on female health.

Holt (2010) examined the relationship between health and labour force participation using data from the first three waves of the Survey of Family, Income and Employment (2002/05). The results of the standard pooled regression models including chronic diseases indicated that five out of nine chronic diseases have significant negative relationship with labour force participation. This suggested that the presence of disease is associated not only with lower participation but also with few working hours. Results of the pooled regression models for selfrated health indicated that poorer self-rated health is associated with a reduced chance of participating in the labour force.

Ghatak and Madheswaran (2014) examined the impact of health on labour supply behavior and wages using the information collected from 676 respondents at selected villages in west Bengal from 2009 to 2010.2 The methodology of the study followed a household production function model. The information on hours of work for each individual respondent was used to measure the labour supply while body mass index (BMI) was used to capture the nutritional dimension of health .Nutritional dimension of health as indicated by BMI found to have a positive and significant impact on labour supply for both the male and female respondents.

Dogrul (2015) examined the relationship between health status and the labour force participation in Turkey by utilizing data from the Turkish Household income and Living Condition Survey. Considering possible endogeneity of health, health equation and labour force participation equation were estimated simultaneously by applying a twostage estimation method. The estimation was carried out respectively for four age-gender groups (men 15-49, women 15-49, men 50-64 and women 50-60). The results of the study suggested that health has positive and significant effect on the labour force participation for all age-gender groups. The effect was larger for older men and younger women. The study also found that labour force participation has significant positive effect on health for younger men and significant negative effect on health for older women. 
Nwosu and Woolard (2015) investigated the impact of health on labour force participation using South Africa as a case study. The study was motivated as South Africa has experienced significant disease burden especially due to communicable diseases like HIV/AIDS and tuberculosis and conditions like obesity and declining labour force participation in the country. The data was sourced from the first and third waves of the National Income Dynamic Study, a nationally representative panel dataset of South Africa households and a rich source of health and socioeconomic data. The study found that endogenous treatment of self-assessed health in a contemporaneous setting suggested positive and significant impact of health on labour force participation.

\subsection{Studies Relevant to Pakistan}

Farid et al. (2012) traced out the human capital related factors which determine employment in Pakistan. The study was based on primary source of data which was collected from 494 households of district Bahawalpur, Pakistan by employing multistage cluster sampling technique. The study used both the quantitative and qualitative variables and Binomial Logit regression model technique was used to estimate the parameters of labour force participation model. The study concluded that the complete years of education, experience, various level of education, health status of workers have significant influence on the labour force participation and employment. In addition, it was found that some socio economic factors like households' assets, spouse participation in economic activities and number of dependents also have significant impact on the employment.

Bashir et al. (2012) analyzed the effect of education and health on employment in Pakistan. The study used time series data for the period 1972-2010. The study also incorporated the causality based on VAR and VECM. The study applied Johansen Co-integration test for reliable long run estimates and Vector Error Correction model for short-run analysis. The long-run results suggested that government expenditures on health and education, investment, total enrollment in education and number of hospitals are the significant factors those are inducing employment in Pakistan while the short-run variables are converging towards long-run equilibrium by taking 7 percent annual adjustment.

Mushtaq et al. (2013) analyzed the impact of health on changing labour force participation during Pakistan economic transition in the 1980s. The study employed Autoregressive Distributed Lag model (ARDL) cointegration technique to estimate the short-run and long- run elasticities. To determine the dynamic shot -run causality between the variables during the period 1975-2011, the study used Wald Co-efficient restrictions test. The few variables included in the study were age dependency, health expenditures, trade openness, population per bed, life expectancy, gross capital formation, mortality rate, secondary school enrolment and labour force participation rate. The study concluded that infant mortality rate, gross capital formation and secondary school enrolment reduce labour force participation in the long run however these results invert the relationship in the short run. The study also found that health expenditures has positive and significant impact on labour force participation in the short-run but this result was not observed in the long run. The results also showed that trade liberalization has positive effect on labour force participation of Pakistan in short run while there was negative effect in the long run.

Shaheen et al. (2015) investigated the factors that determine female employment status in Pakistan. Primary data was collected through field survey consisting of 402 females in district Sahiwal. By employing binomial and multinomial logistic regression model the study found that age, educational attainment, marital status and presence of children above 10 years have a positive impact on female employment while presence of children below 10 years, assets ,major disease and household size have negative and significant impact on female employment status in Pakistan.

The above cited literature linked both health and labor force participation taking the case of developed counties for analysis while very less attention has been paid for developing countries. The cited literature, mostly, took primary data and self-reported health as a unit of analysis. This study contributes to the literature by taking secondary data for analysis. Furthermore this study employed relatively new technique called Autoregressive 
Distributive Lag Model for estimation purposes which is best suited for a small sample size, a case of this particular study.

\subsection{Model Specification, Data and Methodology}

\subsubsection{Empirical Model}

To find out the impact of health on labor force participation rate the following general model is estimated:

$$
Y_{t}=\beta_{o}+\beta_{1} X_{t}+\beta_{2} Z_{t}+\mu t
$$

Here in this equation $\mathrm{Y}_{\mathrm{t}}$ is Labour force participation rate, $\mathrm{X}_{\mathrm{t}}$ is health expenditure which is variable of interest, $\mathrm{Z}_{\mathrm{t}}$ stands for Vector of control variables that include secondary school enrolment ratio, gross fixed capital formation and trade openness, and $\mu_{t}$ is error term.

The specific econometric form of the model is as following;

$$
l f p r_{t}=\beta_{o}+\beta_{t} h_{e x}+\beta_{2} l e_{t}+\beta_{s} s s e r_{t}+\beta_{t} g f c f_{t}+\beta_{5} T O_{t}+\varepsilon_{t}
$$

Where $\beta$ 's are parameters, $l f p r t$ is the Labor force participation rate which is proportion of population ages 1565 that is economically active, hex, is the total health expenditure. This specific variable is measured as the percentage of GDP. le $e_{\hbar}$ is Life expectancy at birth means a number of years a newborn infant would live if prevailing patterns of mortality at the time of its birth were to stay the same throughout its life. Life expectancy is measured in years. sser, Secondary School Enrollment is the extent of the number of inhabitants in the official age for optional training as per the national controls who are really selected in optional schools. It is estimated as level of gross enlistment for male and female. $g f f_{t}$ is Gross fixed capital formation (formally gross domestic investment) includes land improvements (fences, ditches, drains and so on); plant, machinery and equipment purchases; and the construction of roads, railways, and the like including schools, offices, hospitals, private residential dwellings and commercial and industrial buildings.Gross capital formation is measured as a percentage of GDP., $\mathrm{TO}_{t}$ is Trade openness which is the removal or reduction of restrictions or barriers on the free exchange of goods between nations. This includes the removal or reduction of both tariff (duties and surcharges) and non-tariff obstacles (like licensing rules, quotas and other requirements). The easing or eradication of these restrictions is often referred to as promoting "free trade". Trade openness is measured in imports and exports of goods and services as percentage of

GDP. Subscript " $\mathrm{t}$ " is time variant and $\varepsilon_{t}$ is the error term.

\subsection{Data}

To meet the objective of the study, annual time series data is collected from 1972 to 2013.Two main sources that were used to collect the required data include various publication of Economic Survey of Pakistan and World Development Indicator (WDI). Data on all the selected variables is collected from WDI except Health Expenditure. The data on this specific variable is collected from economic survey of Pakistan.

\subsection{Estimation Technique}

The estimation of a model is made through application of Auto-Regressive Distributed Lag (ARDL) technique developed in Pesaran and Shin (1999) and Pesaran et al. (2001) and summarized in Giles et al. (2011). This specific approach is applicable in case where there is mix order of integration and having small sample size. The recognized form of this approach is articulated in current and lagged values of the regressors and regressand.

Three steps are involved in completion of ARDL, where in step one, on the basis of Wald F- Statistics the decision of cointegration is made, one can confront with three different situations either the calculated value of Wald F-statistics exceeds the tabulated upper bound of Wald F-statistics, it may be less than the lower boundary 
and it may lie in between the upper and lower boundaries. If the calculated value is greater than the upper boundary at $5 \%$ level of significance it is evident for long run cointegration, if lower than the lower boundaries, it signify no long run cointegration and in case where it lies in between the two boundaries that implies that the decision is inconclusive.

Once the long run cointegration is established, next long run elasticities are estimated and in the final step short run dynamics are extracted.

\section{RESULTS AND DISCUSSION}

\subsection{Unit Root Analysis}

Econometric modeling of time series data depends on stationarity analysis where the decision for unit root is made. If the series has a unit root then the classical regression methods misguide as it become spurious in presence of unit root in the data and vice versa. Therefore this study conducted unit root analysis by employing Augmented Dickey-Fuller (ADF) test. Table 1 shows the result when the null hypothesis of non-stationarity ("unit root") is tested without a trend term - "ADF $(\mathrm{C})$ ", and with a trend term - "ADF $(\mathrm{C}, \mathrm{T})$ ”. (Lag lengths for the ADF test regressions were determined by minimization of the Schwarz information criterion (SIC).

Table-4.1. Augmented Dickey Fuller (ADF) Test Result

\begin{tabular}{l|l|l|l|l}
\hline Variables & \multicolumn{2}{c}{ Level } & \multicolumn{2}{c}{$\mathbf{1}^{\text {st }}$ Difference } \\
\hline & $\mathbf{C}$ & $\mathbf{C}, \mathbf{T}$ & $\mathbf{C}$ & $\mathbf{C}, \mathbf{T}$ \\
\hline $\mathrm{LFPR}_{\mathrm{t}}$ & $0.0647(0.9590)$ & $-1.2534(0.8853)$ & $-5.6039(0.0000)$ & $-5.9231(0.000)$ \\
\hline $\mathrm{HEX}_{\mathrm{t}}$ & $-2.0325(0.2723)$ & $-2.4740(0.2266)$ & $-4.0902(0.0001)$ & $-4.7348(0.000)$ \\
\hline $\mathrm{LE}_{\mathrm{t}}$ & $-10.4909(0.000)$ & -10.8679 & $\ldots \ldots$ & $\ldots$. \\
\hline $\mathrm{SSER}_{\mathrm{t}}$ & $0.1912(0.2047)$ & $-2.1696(0.4931)$ & $-6.9662(0.0000)$ & $-6.8342(0.000)$ \\
\hline $\mathrm{GFCF}_{\mathrm{t}}$ & $-2.2136(0.2047)$ & $-2.1696(0.4931)$ & $-5.9910(0.0000)$ & $-5.8840(0.000)$ \\
\hline $\mathrm{TO}_{\mathrm{t}}$ & $-3.3741(0.0178)$ & $-3.8543(0.000)$ & $\ldots \ldots$ & $\ldots \ldots$ \\
\hline Note: Authors Calculation & & &
\end{tabular}

The above table evident that life expectancy and trade openness are stationary at level while rest of other variables are integrated of order one. It is concluded from the table that there is mix order of integration which is an evidence for the application of ARDL.

\section{LAG LENGTH SELECTION CRITERIA}

After analysing the unit root testing the next step is to choose lag length for co integration because the number of lags capture the dynamics of series. There are different criterions for selection of optimal lag length. The results of different criterions are in Table 2 below.

Table-2. Selection of lag length

\begin{tabular}{l|l|l|l|l|l}
\hline LAG & LR & FPE & AIC & SC & HQ \\
\hline $\mathrm{O}$ & NA & 7.325049 & 19.01850 & 19.27183 & 19.11010 \\
\hline 1 & 551.9324 & $2.47 \mathrm{e}-06$ & 4.093277 & $5.866600^{*}$ & 4.734454 \\
\hline 2 & $74.52492^{*}$ & $1.07 \mathrm{e}-06^{*}$ & $3.133095^{*}$ & 6.426410 & $4.23853^{*}$ \\
\hline
\end{tabular}

Amongst the different criteria's the one will be choose which has a minimum value and in that particular case Akaike Information Criterion (AIC) has a minimum value and thus selected as a lag length criteria for this study.

\subsection{Long Run Cointegration Analysis}

As stated earlier, the long run cointegration decision is made through the value of Wald F-Statisitics. The results are presented as following; 
Table-3. Cointegration Analysis

\begin{tabular}{l|l|l}
\hline Computed F-statistic 20.9108 & & \\
\hline Critical bound & Lower bound & Upper bound \\
\hline Critical bound's value at 1 percent & 2.75 & 3.79 \\
\hline Critical bound's value at 5 percent & 3.12 & 4.25 \\
\hline
\end{tabular}

It is clear from the above table 3 that there exist long run cointegration as the calculated value of Wald $\mathrm{F}$ statistics is greater than the upper boundary at $1 \%, 5 \%$ and $10 \%$ level of significance.

\subsection{Long and Short Run Elasticities}

Once the long run cointegration is established, in next step the long run and short run elasticities are estimated and the results are following;

Table-4.4. Dependent variable is $\mathrm{LFPR}_{\mathrm{t}}$ (Labor Force Participation Rate)

\begin{tabular}{l|l|l}
\hline Variables & Long Run Coefficients & Short Run Coefficients \\
\hline $\mathrm{HEX}_{\mathrm{t}}$ & $1.1917^{* *}$ & $0.89120^{* *}$ \\
\hline $\mathrm{LE}_{\mathrm{t}}$ & $-2.6835^{*}$ & 6.4167 \\
\hline $\mathrm{SSER}_{\mathrm{t}}$ & $0.3256^{*}$ & $0.929^{* *}$ \\
\hline $\mathrm{GFCF}_{\mathrm{t}}$ & $0.1307^{* *}$ & $0.8012^{* *}$ \\
\hline $\mathrm{TO}_{\mathrm{t}}$ & 0.00186 & 0.0012 \\
\hline $\mathrm{Ecm}_{(-1)}$ & $\ldots .$. & $-0.672^{*}$ \\
\hline $\mathrm{R}^{2}$ & 0.66 & 0.65 \\
\hline Adj. $\mathrm{R}^{2}$ & 0.57 & 0.55 \\
\hline D.W.-Statistic & 2.0167 & 2.0101 \\
\hline F-stat. & $4.7654(0.000)$ & $6.3421(0.000)$ \\
\hline Note:******* significance at the $1 \%, 5 \%$ and $10 \%$ level respectively and values in Parentheses are probabilities.
\end{tabular}

The results reveals that there is positive and significant association between health and labor force participation. These findings are also supported by Bashir et al. (2012). Health in our model is proxy by health expenditure. With every $1 \%$ increase in health expenditure labor force participation increased more than unity in long run and $81 \%$ in short run respectively. The results indicate that an increase in health expenditures brings improvements in health conditions which helps active participation in every economic activity. Increase in economic activity will creates employment opportunities and thus increase labor force participation.

Life expectancy has negative impacts on labor force participation. The findings are statistically significant in long run while insignificant in short run. One probable justification can be a probability of experiencing chronic and acute health shocks which increase considerably with increase in age and cause individual to leave the labor market.

School Enrolment also helps an increase in labor force participation. The results of the study reveals that with every $1 \%$ increase in enrolment ratio at secondary school level helps $32 \%$ labor force participation is increased in long run and $92 \%$ in short span of time. The results shows that with increase in education, labor get skills and thus has more opportunities in market which increase participation ratio.

Investment is also positively associated with labor force participation. It is shown that with every $1 \%$ increase in investment labor force participation rate is increased by $13 \%$ and $80 \%$ respectively. Investment has always been a source of increased labour force participation rate. Investment in new projects creates job opportunities among the people that lead to increased labour force participation rate.

The results of trade openness is surprisingly insignificant both in long and short run. Error Correction Mechanism shows a high speed of adjustment to the disequilibrium that occur at long run. Its value enter in the model with negative sign as expected. 


\section{DIAGNOSTIC TEST}

Our model specification satisfied all the diagnostic tests. Table 5 represent the results of these tests. The results presents in table below suggest that the estimation of long-run coefficients and ECM are free from serial correlation, heteroscedasticity, functional form and non-normality. The variation in dependent variable explained by explanatory variable suggest that the model is good fit and the $66 \%$ variation are explained by these explanatory variables that occur in dependent variables. The value of F-statistic is 4.7654 which shows that the explanatory variables are important determinant of labor force participation. CUSUM and CUSUMQ plots are used to analyse the soundness of long run parameters along with the short run movements for unrestricted Error Correction Model shows that our model is steady.

Table-5. Diagnostic Tests

\begin{tabular}{l|l}
\hline A:Serial Correlation & $0.00803(0.929)$ \\
\hline B:Functional Form & $0.0574(0.811)$ \\
\hline C:Normality & $1.7326(0.420)$ \\
\hline D:Heteroscedasticity & $3.019(0.082)$ \\
\hline
\end{tabular}

A:Lagrange multiplier test of residual serial correlation B:Ramsey's RESET test using the square of the fitted values of C: Based on a test pf skewness and kurtosis of residuals D: Based on the regression of squared residuals on squared fitted values

Plot of Cumulative Sum of Squares of Recursive Residuals

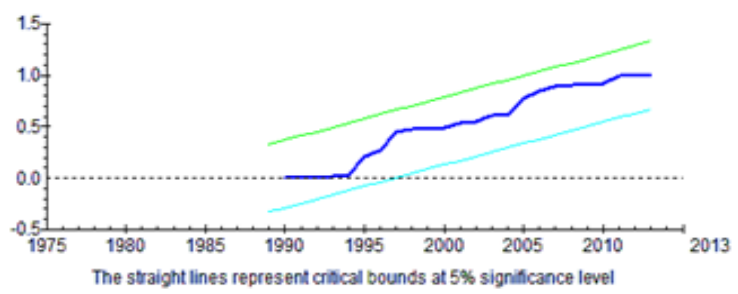

Plot of Cumulative Sum of Recursive Residuals

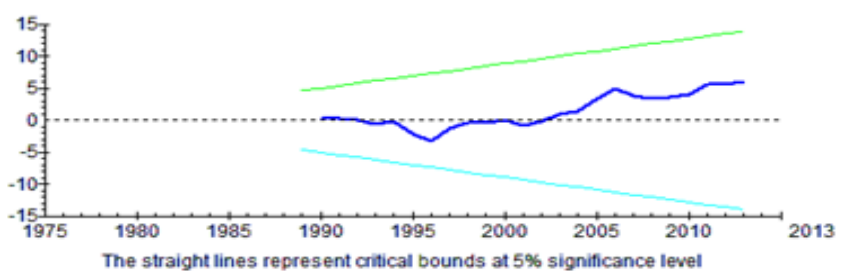

Fig-1. CUSUM and CUSUMQ plots

\section{CONCLUSION AND RECOMMENDATIONS}

Impacts of health on labor force participation rate was analysed in this study. Autoregressive Distributive Lag model was used to test the hypothesis of the study. The results revealed that labor force participation is increased by increased in health expenditure, secondary school enrolment and Investment both in short and long run. Life expectancy shows negative association with labor force participation and trade openness has insignificant impacts on labor force participation rate in Pakistan. On the basis of these findings it can be suggested that government may increase the health expenditures for betterment of economy which can be stimulate through higher labor force participation. Not only that but also the key issue that effect the health status of people ought to be addressed through a diverse set of policy tools comprising short and long term measures to secure better health outcomes. Investment as a percentage of GDP must be increased, as higher investment will directly lead to higher labour force participation rate in a country. There is need to build new education and training institutes that will lead to increase in literacy rate and it will ultimately lead to increased labor force participation rate.

Funding: This study received no specific financial support.

Competing Interests: The authors declare that they have no competing interests.

Contributors/Acknowledgement: All authors contributed equally to the conception and design of the study. 


\section{REFERENCES}

Bashir, F., S. Farooq, S. Nawaz, M. Bagum, M.A. Sandila and M.R. Arshad, 2012. Education, health and employment in Pakistan: A co-integration analysis. Humanities Research Social Sciences, 2(5): 53-64.

Becker, G., 1964. Human capital: A theoretical and empirical analysis, with special reference to education. 3rd Edn., Chicago: The University of Chicago Press.

Cai, L., 2010. The relationship between health and labour force participation: Evidence from a panel data simultaneous equation model. Labour Economics, 17(1): 77-90.Available at: https://doi.org/10.1016/j.labeco.2009.04.001.

Cai, L. and G. Kalb, 2004. Health status and labour force participation: Evidence from the HILDA data. Melbourne: Institute of Applied Economic and Social Research.

Cai, L. and G. Kalb, 2006. Health status and labour force status of older working-age Australian men. Australian Journal of Labour Economics, 15(3): 241.261.Available at: http://doi.org/10.1002/hec.1053.

Chirikos, T.N., 1993. The relationship between health and labor market status. Annual Review of Public Health, 14(1): 293312.Available at: https://doi.org/10.1146/annurev.publhealth.14.1.293.

Dogrul, H.G., 2015. The effects of health on labour force participation: Evidence from Turkey. International Journal of Economics and Finance, 7(8): 168-181.Available at: 10.5589/ijef.v7n8p168.

Dwyer, D.S. and O.S. Mitchell, 1999. Health problems as determinants of retirement: Are self-rated measures endogenous? Journal of Health Economics, 18(2): 173-193.Available at: https://doi.org/10.1016/s0167-6296(98)00034-4.

Farid, M.Z., I.S. Chaudhary and M.S. Malik, 2012. How does human capital formation affect labour force participation in Pakistan? A primary data analysis. Canadian Social Science, 8(4): 162-171.

Ghatak, A. and S. Madheswaran, 2014. Impact of health on labour supply and wages a case of agricultural workers in West Bengal. Journal of Health Management, 16(3): 441-457.Available at: https://doi.org/10.1 177/0972063414539617.

Giles, J., W. Dewen and C. Wei, 2011. The labor supply and retirement behavior of China's older workers and elderly in comparative perspective. Policy Research Working Paper 5853, World Bank, Development Research Group.

Grossman, M., 1972. On the concept of health capital and the demand for health. Journal of Political Economy, 80(2): 223255.Available at: https://doi.org/10.1086/259880.

Holt, H., 2010. Health and labour force participation (No. 10/03). New Zealand Treasury.

Holt, H., 2010. The cost of ill health (No. 10/04). New Zealand Treasury.

Leung, S.F. and C.T. Wong, 2002. Health status and labor supply: Interrelationship and determinants.

Mushtaq, A., A. Mohsin and K. Zaman, 2013. Effects of health on changing labor force participation in Pakistan. Springer Plus, 2(1): 610.Available at: 10.1186/2193-1801-2-610.

Nwosu, C.O. and I. Woolard, 2015. Impact on health on labour force participation in South Africa (No. 548).

Pandey, M.K., 2009. Labor force participation among indian elderly: Does health matter? Pakistan Economic Survey $2015-2016$.

Pesaran, M.H. and Y. Shin, 1999. An autoregressive distributed lag modeling approach to cointegration analysis, In: Strom, S., Holly, A., Diamond, P. (Eds.), Centennial Volume of Rangar Frisch. Cambridge: Cambridge University Press.

Pesaran, M.H., Y. Shin and R.J. Smith, 2001 . Bounds testing approaches to the analysis of level relationships. Journal of Applied Econometrics, 16(3): 289-326.Available at: https://doi.org/10.1002/jae.616.

Shaheen, R., G. Shabir, M.Z. Faridi and F. Yasmin, 2015. Determinants of female employment status in Pakistan: A case of Sahiwal District. Pakistan Journal of Commerce and Social Sciences, 9(2): 418-437.

Views and opinions expressed in this article are the views and opinions of the author(s), Asian Journal of Economic Modelling shall not be responsible or answerable for any loss, damage or liability etc. caused in relation to/arising out of the use of the content. 